\title{
Rancang Bangun Pengendalian Robot Mobil dengan Wireless Joystick PS2 Menggunakan Modul nRF24L01
}

Arif Rahman Hakim¹, Nehru², dan Samratul Fuady ${ }^{3}$

${ }^{1}$ Program Studi Teknik Elektro, Fakultas Sains dan Teknologi, Universitas Jambi, Indonesia

Email: arifx02@gmail.com, nehruunja@gmail.com, sfuady@unja.ac.id

\section{Info Artikel}

Diterima: 25 Juli 2021

Disetujui: 16 Agustus 2021

Dipublikasikan: 31 Agustus 2021

\section{Alamat Korespondensi:} arifx02@gmail.com

Copyright (c) 2021 Jurnal

Engineering

This work is licensed under the Creative Commons Attribution International License (CC BY 4.0).

\begin{abstract}
Abstrak
Robot adalah sebuah alat mekanik yang dapat melakukan tugas fisik baik menggunakan pengawasan dan kontrol manusia, atau program yang sudah tertanam dalam sebuah processor. Dalam suatu pengendalian sistem robot manual, sebagai bentuk komunikasi atau interaksi manusia dengan robot, maka perlu alat yang digunakan untuk komunikasi antara manusia dengan robot, salah satunya adalah telekomunikasi nirkabel. Modul nRF24L01 adalah transceiver chip tunggal yang khusus di desain untuk menyediakan pengaplikasian komunkasi wireless dengan daya yang sangat rendah. Penelitian ini menggunakan dua buah modul nRF24L01 dan dua buah mikrokontroler sebagai media komunikasi. Satu modul nRF24L01 berfungsi sebagai transmitter dan satu modul nRF24L01 sebagai receiver. Robot yang dibuat dapat dikendalikan melaui analog joystick PS2 yang terdapat pada bagian transmitter. Berdasarkan penelitian yang sudah dilakukan dapat diambil kesimpulan bahwa robot yang dibuat dapat dikendalikan menggunakan kontroler dengan jarak maksimal 300 meter.

Kata kunci: Robot, nRF24L01, Joystik Analog
\end{abstract}

\section{Pendahuluan}

Robot adalah sebuah alat mekanik yang dapat melakukan tugas fisik baik menggunakan pengawasan dan kontrol manusia, atau program yang sudah tertanam dalam sebuah processor (Nugroho, 2019). Salah satu jenis bentuk robot yang sering dikembangkan oleh developer robotika adalah Robot Manual Mini Industri. Robot manual mini industri merupakan robot transporter yang dilengkapi dengan gripper dan dikontrol manual oleh pengguna melalui joystick controller baik dengan media kabel maupun wireless. Robot manual dengan kontrol joystcik kabel sangat tidak effisien dalam penggunaanya sehingga dilakukan penelitian tentang wireless joystick. Namun pada wireless joystick saat ini masih menggunakan metode single channel sehingga menghilangkan kemampuan multitasking seperti yang ada pada robot joystick kabel (Hariyadi et al, 2020).

Teknologi wireless sudah banyak digunakan pada dunia telekomunikasi dikarenakan sangat fleksibelnya komunikasi wireless dibandingkan dengan komunikasi on wire. Pemanfaatan teknologi komunikasi wireless sudah digunakan secara luas mulai dari pertanian, pemantauan, dan juga pada survey lokasi (Septianto, 2020). 
Penelitian ini bertujuan untuk merancang bangun sebuah robot yang mampu dikendalikan dengan menggunakan kontroler wireless. Digunakan dua buah mikrokontroller yang saling berkomunikasi secara wireless agar alat ini dapat bekerja. Sebuah mikrokontroler berada di dalam robot yang terhubung ke receiver, dan satunya lagi berada di dalam joystick yang tehubung ke transmitter.

\section{Metode Penelitian}

Bagian ini menjelaskan tahapan perancangan yang dilakukan oleh peneliti selama melakukan penelitian ini. Gambar 1 menunjukkan blok diagram keseluruhan sistem yang dibangun. Bagian input yang dikendalikan oleh mikrokontroler Arduino Nano (Tx) meliputi sensor analog yang terdapat pada joystick PS2/PC. Inputan data yang diambil dari nilai analog joystick ini diteruskan oleh mikrokontroler Arduino Nano (Tx) ke modul wireless (modul nRF24L01) untuk dikirimkam kepada modul wireless (modul nRF24L01) yang berada pada model robot mobil untuk kemudian diterima oleh mikrokontroler Arduino Uno $(\mathrm{Rx})$ untuk mendapatkan output yang berupa pergerakan motor DC. Bagian output yang dikendalikan oleh Arduino Uno (Rx) meliputi kecepatan perputaran dari motor DC berdasarkan besarnya nilai analog yang telah diterima dari mikrokontroler yang berada pada joystick.

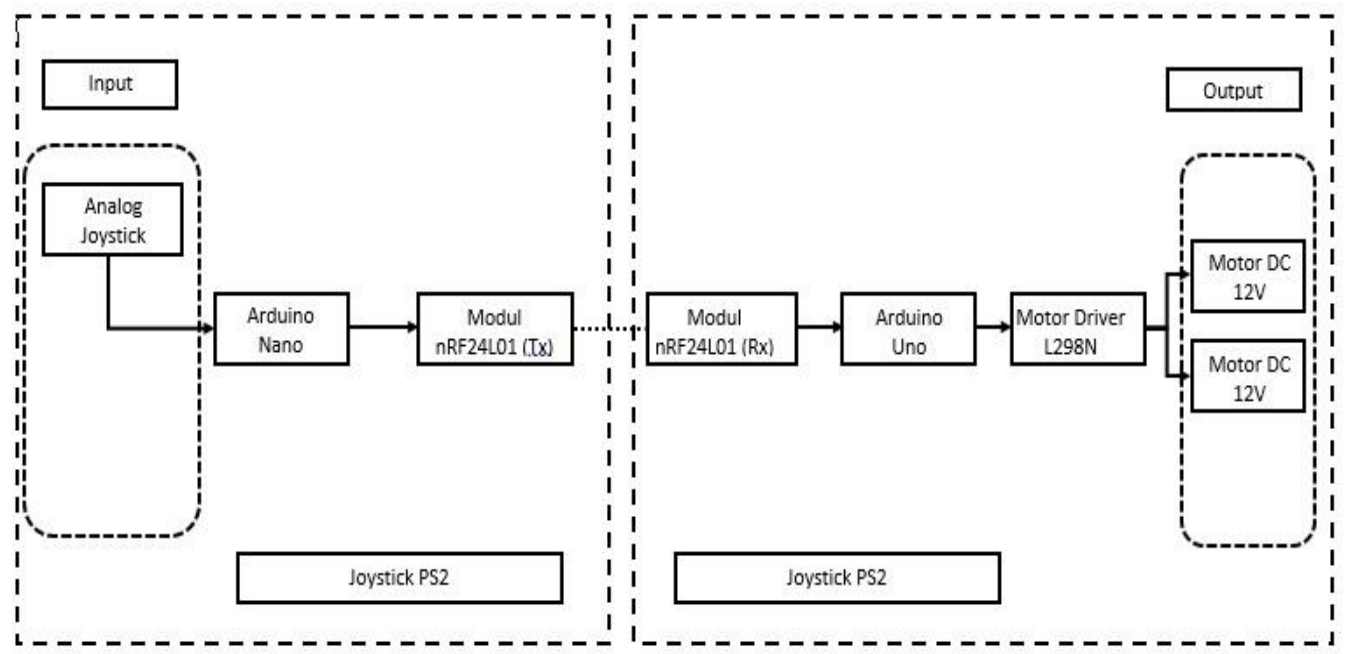

Gambar 1. Blok Diagram Instrumen

\subsection{Perancangan Hardware}

Perancangan perangkat keras terdiri dari dua bagian, bagian pertama adalah pembuatan perancangan bagian model dari robot mobil, dan bagian kedua adalah pembuatan perancangan bagian kontroler joystick.

Pada bagian model robot mobil (Gambar 2 dan 3) terdapat Arduino Uno sebagai otak dari robot, Driver motor sebagai pengatur PWM dari arduino ke motor DC, modul nRF24L01 sebagai penerima (Receiver) sinyal dari kontroler, dan Motor DC sebagai penggerak Robot Mobil. Sedangkan pada bagian kontroler joystick terdapat Arduino Nano, Modul nRF24L01 sebagai Pengirim (Transmitter) sinyal, dan sensor dari analog joystick sebagai masukan data untuk menggerakkan robot mobil (Gambar 4). 


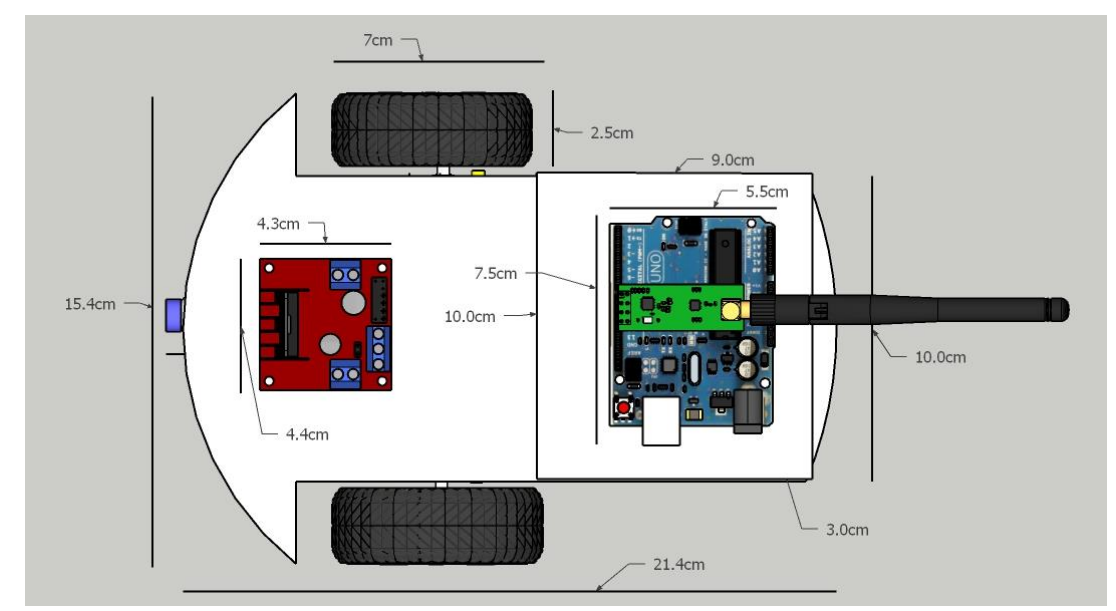

Gambar 2. Desain Model Robot tampak atas

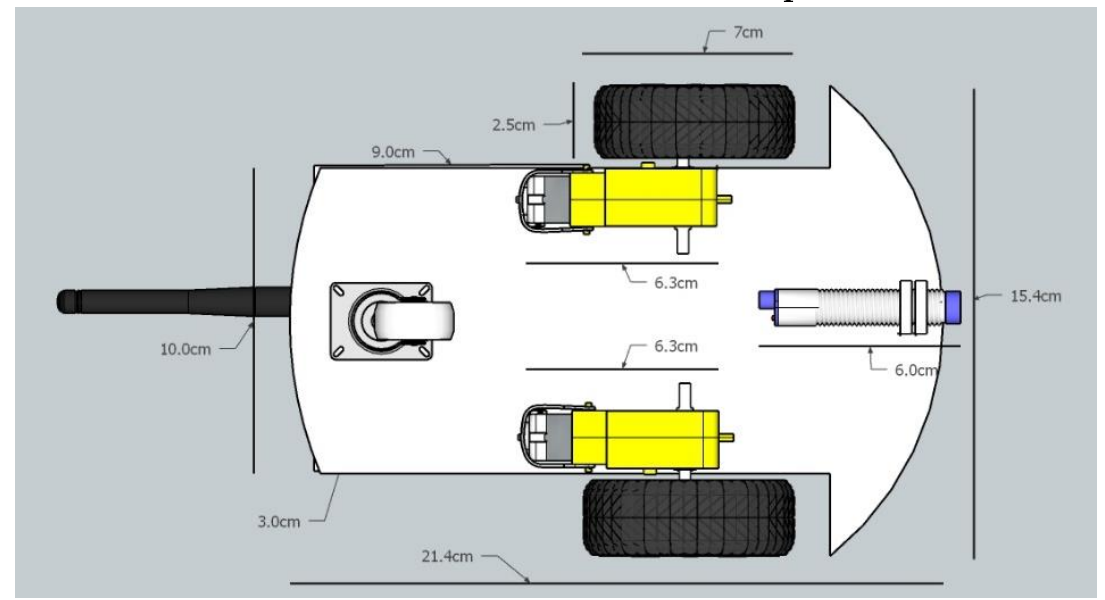

Gambar 3. Desain Model Robot tampak bawah

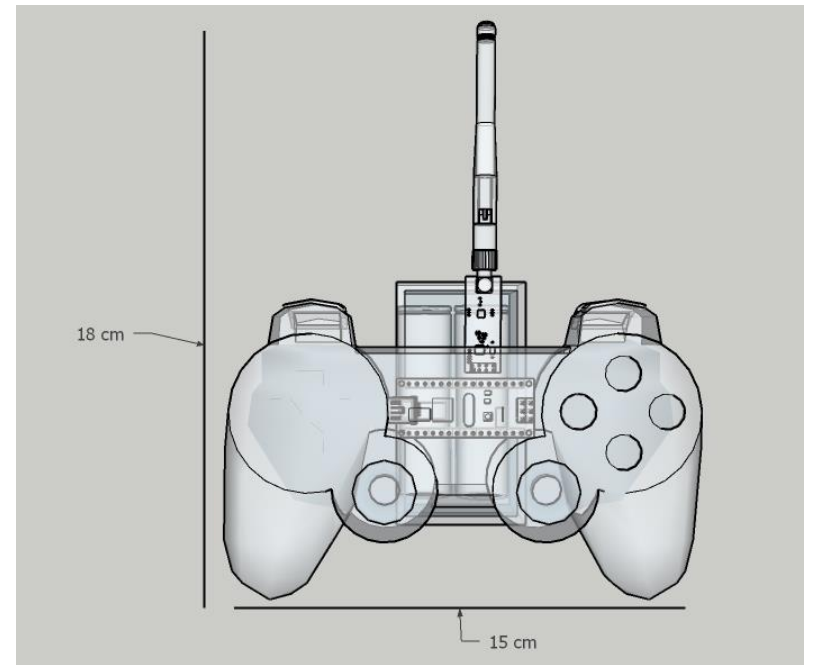

Gambar 4. Desain model kontroler robot

\subsection{Perancangan Elektrik}

Dalam penelitian ini penulis memisahkan perancangan elektrik menjad dua bagian yaitu pada bagian pengirim dan bagian penerima. Bagian pengirim dapat dilihat pada gambar 5 , dan hubungan antara masing-masing komponen yang terdapat pada bagian pengirim dapat dilihat pada tabel 1 dan tabel 2 . 


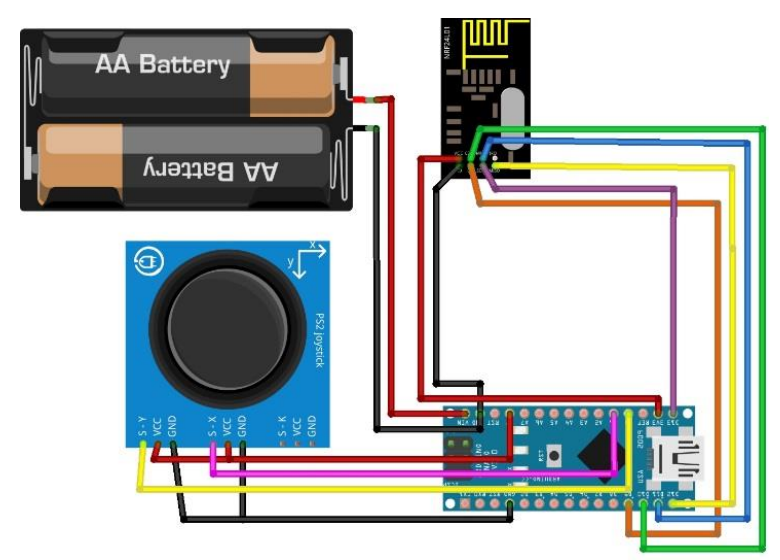

Gambar 5. Rangkaian Transmitter

Tabel 1. Hubungan antara Arduino Nano dan modul Wireless nRF24L01

\begin{tabular}{|c|c|}
\hline Arduino Nano & Modul nRF24L01 \\
\hline Pin $3.3 \mathrm{~V}$ & VCC \\
\hline Pin GND & GND \\
\hline Pin 9 & CE \\
\hline Pin 10 & CSN \\
\hline Pin 13 & SCK \\
\hline Pin 11 & MOSI \\
\hline Pin 12 & MISO \\
\hline
\end{tabular}

Tabel 2. Hubungan antara Arduino nano dan Joystick PS2

\begin{tabular}{|c|c|}
\hline Arduino Nano & Joystick PS2 \\
\hline Pin $5 \mathrm{v}$ & VCC \\
\hline Pin GND & GND \\
\hline Pin A0 & Y Axis \\
\hline Pin A1 & X Axis \\
\hline
\end{tabular}

Bagian penerima dapat dilihat pada gambar 6, hubungan antara masing-masing komponen yang terdapat pada bagian pengirim dapat dilihat pada tabel 3. dan tabel 4 .

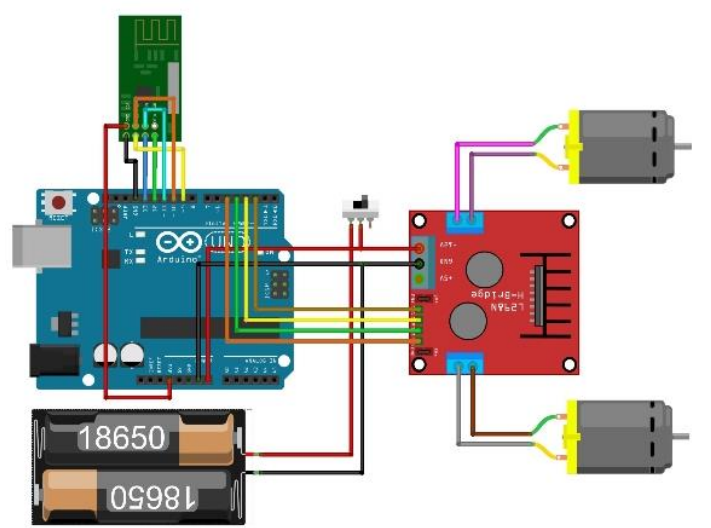

Gambar 6. Rangkain Receiver (Penerima) 
Tabel 3. Hubungan antara Arduino Uno dan modul Wireless nRF24L01

\begin{tabular}{|c|c|}
\hline Arduino Uno & Modul nRF24L01 \\
\hline Pin $3.3 \mathrm{~V}$ & VCC \\
\hline Pin GND & GND \\
\hline Pin 9 & CE \\
\hline Pin 10 & CSN \\
\hline Pin 13 & SCK \\
\hline Pin 11 & MOSI \\
\hline Pin 12 & MISO \\
\hline
\end{tabular}

Tabel 4. Hubungan antara Arduino Uno dan Motor Driver L298N

\begin{tabular}{|c|c|}
\hline Arduino Uno & L298N \\
\hline Vin & VCC \\
\hline Pin GND & GND \\
\hline Pin 2 & In 1 \\
\hline Pin 3 & In 2 \\
\hline Pin 4 & In 3 \\
\hline Pin 5 & In 4 \\
\hline
\end{tabular}

\subsection{Perancangan Software}

Perancangan software ini dibagi menjadi dua bagian yaitu software pada kontroler atau pada bagian pengirim dan software pada robot atau pada bagian penerima seperti terlihat pada gambar 7 .

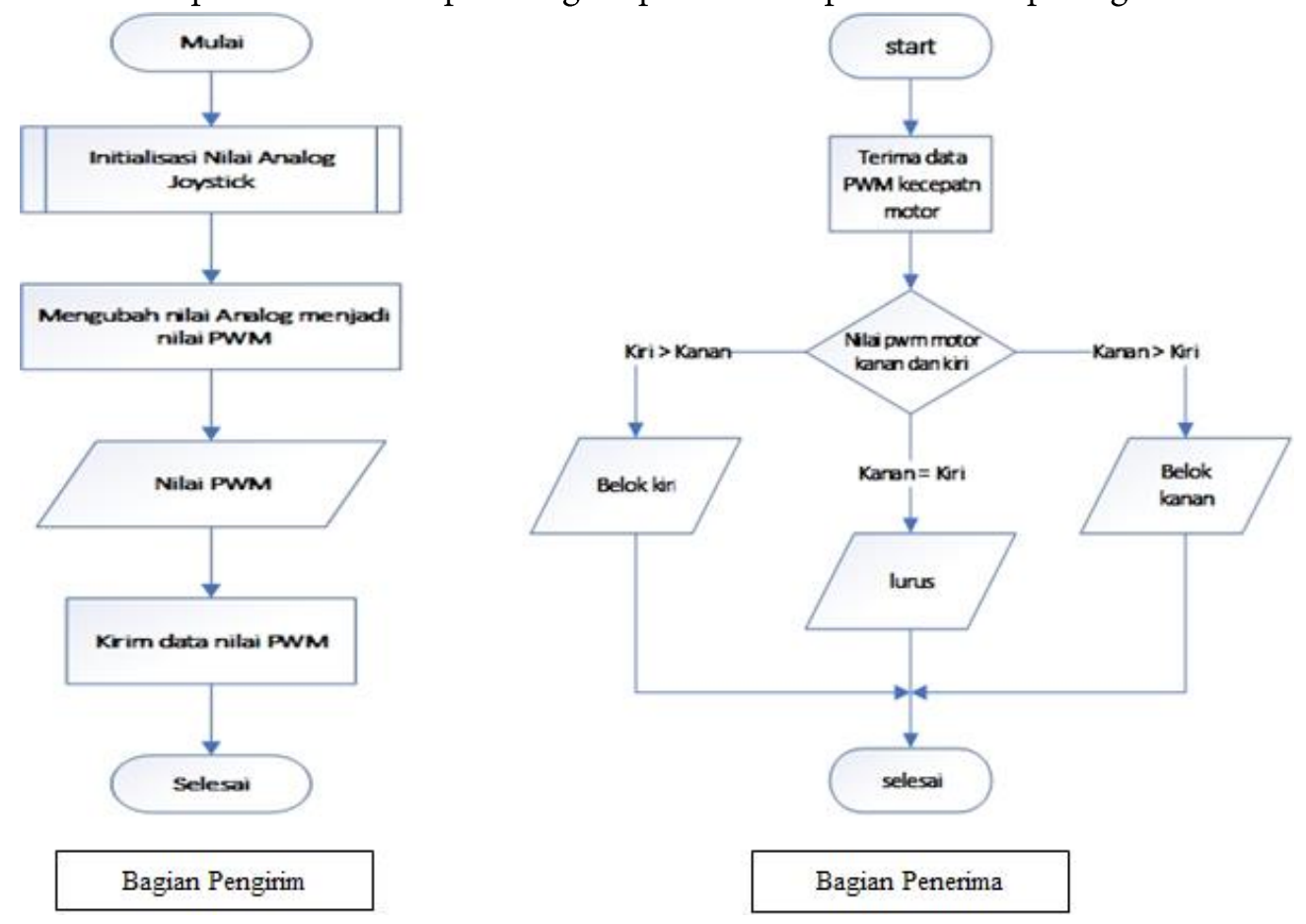

Gambar 1. Prinsip Kerja Sistem bagian pengirim dan penerima 


\subsection{Implementasi Sistem}

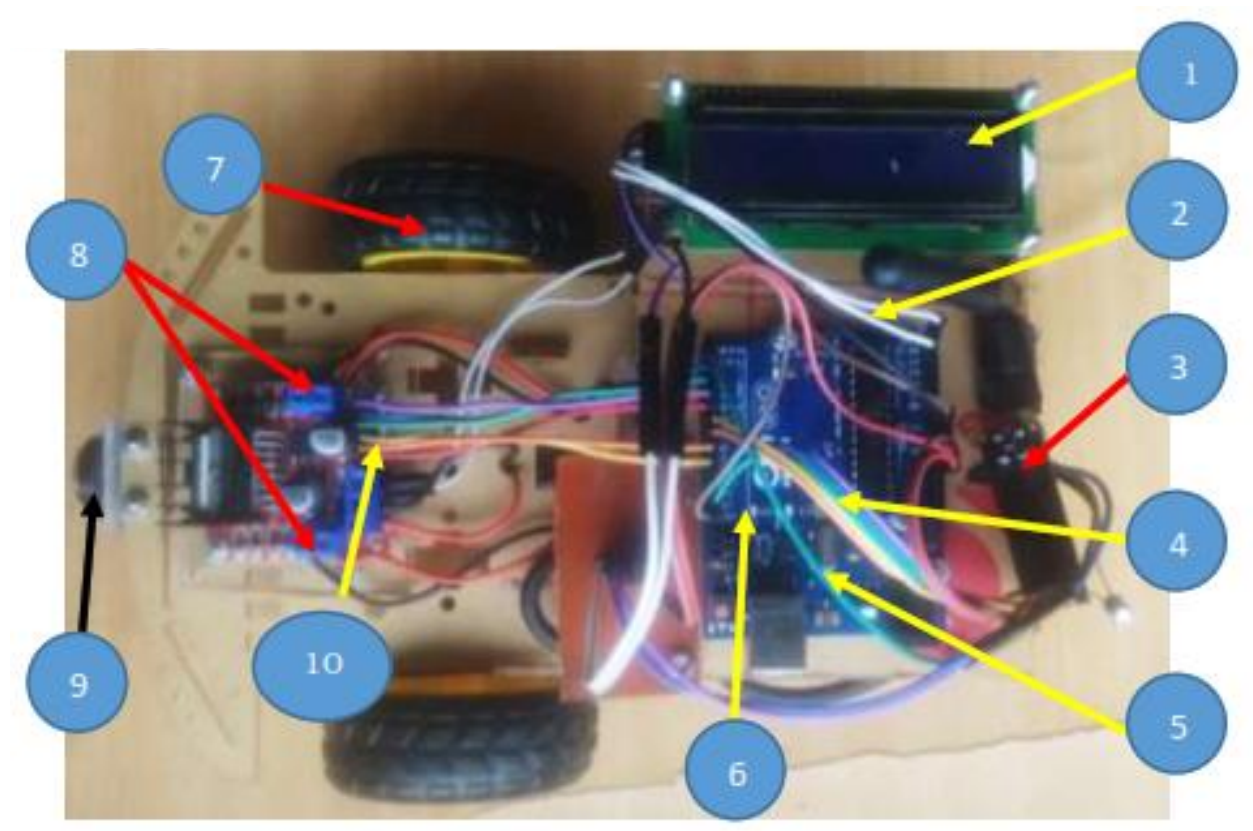

Gambar 7. Rangkaian Penggerak Model Robot Mobil

Keterangan Gambar:

1. LCD (Liquid Crystal Display).

2. SDA dan SCL dari LCD.

3. Modul nRF24L01.

4. Pin CE, CSN, SCK, MOSI, MISO modul nRF24L01 ke Arduino Uno.

5. Pin Input Sensor Proximity IR ke Arduino Uno.

6. Arduino Uno.

7. Roda Mobil terpasang ke Motor DC.

8. Pin Output Motor DC.

9. Sensor Proximity IR.

10. Pin Input Motor Driver.

Pada penggerak model robot mobil dibuat rangkaian yang terhubung pada arduino uno, modul nRF24L01, motor driver L298N, motor dc, dan baterai 18650 7.4V. Tegangan 7.4V dari baterai akan menjadi tegangan masukkan dari motor driver L298N kemudian akan diubah menjadi tegangan $5 \mathrm{~V}$ oleh IC Regulator LM7805 yang akan menjadi inputan dari Arduino Uno.

\section{Hasil Dan Pembahasan}

Hasil dan pembahasan meliputi data hasil pengujian nilai keluaran analog terhadap kecepatan motor dc dan data hasil pengujian jarak komunikasi antar mikrokontroler.

\subsection{Pengujian Pengendalian Joystick}

Untuk menentukan apakah robot dapat dikendalikan dengan menggunakan kontroler joystick dapat dilakukan dengan membandingkan antara arah gerak analog yang terdapat pada kontroler joystick dengan pergerakan robot. Tabel 5 merupakan hasil pembandingan antara arah gerak analog joystick dan arah gerak robot. 
Tabel 5. Hasil Pengujian arah gerak analog joystick terhadap pergerakan robot.

\begin{tabular}{|c|c|c|c|c|c|c|}
\hline No. & Arah Analog & $\begin{array}{c}\text { PWM } \\
\text { Kiri }\end{array}$ & $\begin{array}{l}\text { PWM } \\
\text { Kanan }\end{array}$ & $\begin{array}{c}\text { Motor } \\
\text { Kiri } \\
\text { (rpm) }\end{array}$ & $\begin{array}{l}\text { Motor } \\
\text { Kanan } \\
(\mathrm{rpm})\end{array}$ & Arah Gerak Robot \\
\hline 1. & Tengah & 0 & 0 & 0 & 0 & Tidak Brgerak \\
\hline 2. & Atas & 255 & 255 & 300 & 300 & Maju \\
\hline 3. & Kanan Atas & 255 & 125 & 300 & 147 & Maju Kekanan Secara Perlahan \\
\hline 4. & Kanan & 255 & 0 & 300 & 0 & Berbelok Kekanan \\
\hline 5. & Kanan Bawah & 255 & 125 & 300 & 147 & Mundur Kekanan Secara Perlahan \\
\hline 6. & Bawah & 255 & 255 & 300 & 300 & Mundur \\
\hline 7. & Kiri Bawah & 125 & 255 & 147 & 300 & Mundur Kekiri Secara Perlahan \\
\hline 8. & Kiri & 0 & 255 & 0 & 300 & Berbelok Kearah Kiri \\
\hline 9. & Kiri Atas & 125 & 255 & 147 & 300 & Maju kekiri secara perlahan \\
\hline
\end{tabular}

Berdasarkan hasil analisa data kecepatan motor DC yang didapatkan oleh peneliti dalam pengujian ini, dapat diambil kesimpulan bahwa arah pergerakkan robot dapat menyesuaikan dengan arah pergerakkan dari analog joystick yang terdapat di kontroler. Arah pergerakkan robot diatur dengan adanya perbedaan kecepatan putar dari motor DC kiri dan motor DC kanan. Ketika robot akan berbelok kekiri maka kecepatan putar motor kiri akan lebih pelan daripada kecepatan putar motor dc kanan, sebaliknya apabila robot akan berbelok kearah kanan maka kecepatan putar motor DC kanan lebih pelan daripada kecepatan putar dari motor DC kiri, dan ketika robot akan bergerak maju maupun mundur maka kecepatan putar dari motor DC kiri dan motor DC kanan adalah sama besar.

\subsection{Pengujian Jarak Komunikasi}

Untuk menentukan berapa jarak antara kontroler dengan robot untuk mengontrol robot dapat dilakukan dengan mengukur jauh dari kedua peralatan tersebut yang berlaku sebagai transmitter dan receiver. Pengujian dilakukan dengan menambah jarak antara model robot mobil dengan kontroler joystick dari jarak 10 meter hingga jarak dimana mikrokontroler sudah tidak dapat berkomunikasi lagi (terputus). Dapat dilihat pada tabel 6 hasil pengujian jarak antara kontroler dengan alat yang dibuat.

\begin{tabular}{|c|c|c|c|}
\hline No. & Jarak (M) & Delay $(\mathrm{mS})$ & Kondisi \\
\hline 1 & 10 & 0 & Terhubung \\
\hline 2 & 20 & 0 & Terhubung \\
\hline 3 & 30 & 10 & Terhubung \\
\hline 4 & 40 & 20 & Terhubung \\
\hline 5 & 50 & 50 & Terhubung \\
\hline 6 & 100 & 100 & Terhubung \\
\hline 7 & 150 & 300 & Terhubung \\
\hline 8 & 200 & 700 & Terhubung \\
\hline 9 & 250 & 900 & Terhubung \\
\hline 10 & 300 & 1000 & Terhubung \\
\hline
\end{tabular}




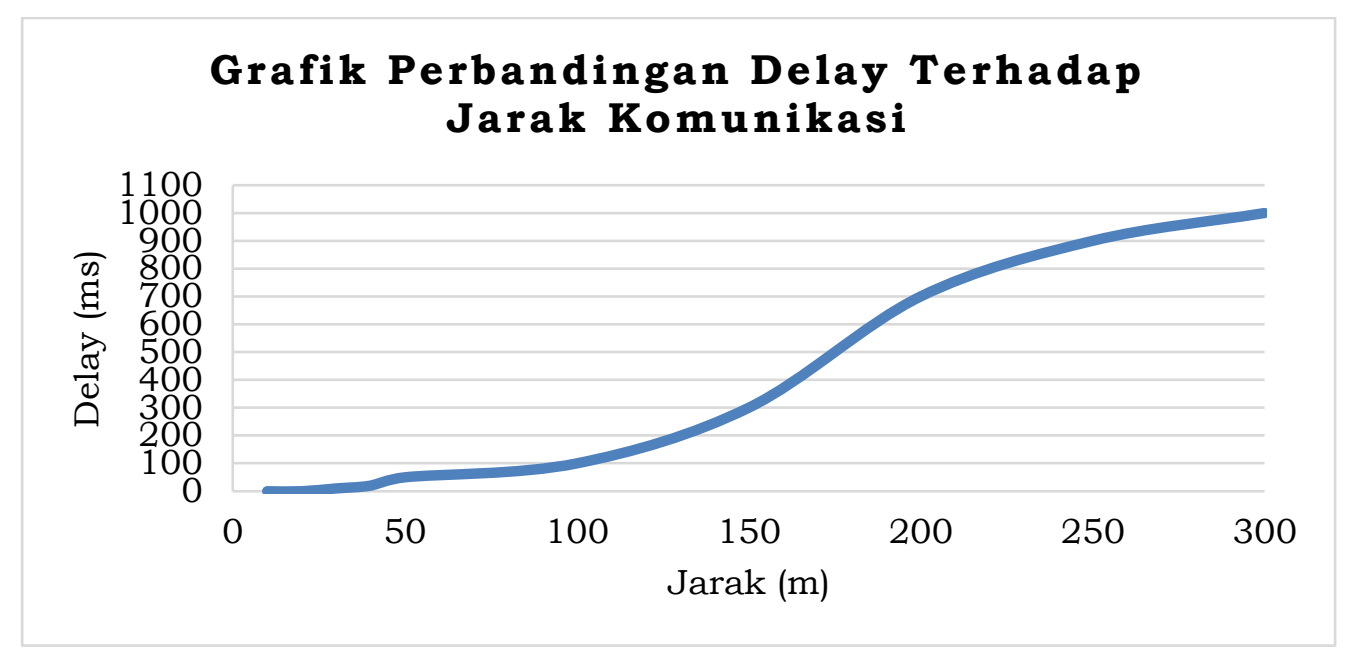

Gambar 9. Grafik Perandingan Delay terhadap Jarak Komunikasi

Dari pengujian jarak komunikasi antara robot dan kontroler dapat diambil kesimpulan yaitu, semakin jauh jarak antara robot dan kontroler maka akan semakin besar pula delay yang tercipta. Selain itu, berdasarkan datasheet dari modul nRF24L01, ketika dipilih kecepatan pengiriman data 2MBPS jarak maksimal yang mampu dicapai adalah 520 meter. Sedangkan pada penelitian ini dengan kecepatan pengiriman 2MBPS hanya mampu berkomunikasi pada jarak 300 meter, hal ini disebabkan oleh pada saat peneliti menuliskan program untuk bagian receiver (penerima) penulis menentukan adalah waktu maksimum yang penerimaan data yang ada pada bagian receiver adalah 1000 milisecond. Oleh karena itu pada penelitian ini jarak maksimum komunikasi antara robot dan kontroler adalah 300 meter karena pada saat jarak tersebut delay yang tercipta adalah sebesar 1000 milisecond.

\section{Kesimpulan}

Berdasarkan penelitian yang sudah dilakukan dapat diambil kesimpulan bahwa Dengan menggunakan modul komunikasi wireless nRF24L01 dapat digunakan untuk mengendalikan sebuah robot mobil menggunakan kontroler wireless dengan jarak 300 meter.

\section{Daftar Pustaka}

[1]. Aprigraha, S., W. Kurniawan dan A. S. Budi. 2019. Implemetasi Metode Complemetary Filter pada Pengendali Robot Mobil menggunakan Gestur Tangan Manusia. Jurnal Pengembangan Teknologi Informasi dan Ilmu Komputer Volume 3. No 10: 9788-9797.

[2]. Hariyadi, A., Y. Ratnawati dan R. H. Y. Perdana. 2020. Transceiver Multi Channels untuk Kontrol Gerak dan Monitoring Kondisi pada Robot Manual Mini Industri. IPTEK-Volume 24. No.1. DOI: 10.31284/j.iptek.2020.v24i1.571

[3]. Nugroho, W. P. 2019. Kontrol Model Pesawat Sederhana Menggunakan Pembacaan Sensor Sarung Tangan. Tugas Akhir, Jurusan Teknik Elektro, FST, Universitas Sanata Darma, Yogyakarta.

[4]. Saptiadi, I., D. Minggu dan Y. Darmawan. 2020. Rancang Bangun Sistem Kendali pada Robot Tempur Menggunakan Joystick Berbasis Arduino. TELKA Volume 6. No.1: 49-55.

[5]. Septiano, A. dan T.Ghozali. 2020. NRF24L01 Sebagai Pemancar/Penerima Untuk Wireless Sensor Network. TEKNO Volume 17. No 1: 24-34. 